\title{
A TRANSMISSÃO DO CONHECIMENTO EM DEBATE: ESTARIA A PEDAGOGIA HISTÓRICO-CRÍTICA REABILITANDO O ENSINO TRADICIONAL?
}

\author{
JULIANA CAMPREGHER PASQUALINI ${ }^{1}$ \\ ORCID: https://orcid.org/0000-0002-6497-8783 \\ TIAGO NICOLA LAVOURA ${ }^{2}$ \\ ORCID: https://orcid.org/0000-0003-4382-0415
}

\begin{abstract}
RESUMO: $O$ artigo se propõe a aprofundar o debate acerca da defesa da transmissão dos conhecimentos científicos, artísticos e filosóficos reivindicada pela pedagogia histórico-crítica no atual contexto político-cultural de obscurantismo e ataques à razão. Com base em investigação teóricoconceitual de tipo bibliográfica, explora as diferenças entre a proposição histórico-crítica e os métodos tradicionais de ensino, sustentando que o combate às pedagogias não-diretivas não outorga um movimento de reabilitação da pedagogia tradicional, marcada pela prevalência do método indutivo, pelo verbalismo e pela apreensão acrítica da relação escola-sociedade. Conclui-se que a pedagogia históricocrítica conserva o princípio da transmissão do conhecimento para todos, mas, uma vez que baseia em outra concepção de conhecimento, realiza-se a partir de outro método e subordina-se a outra finalidade, tal princípio é requalificado, vislumbrando a práxis. Postula-se, enfim, a compreensão da transmissão de conhecimento como princípio de esfera ontológica - e não didática ou operacional - do processo educativo.
\end{abstract}

Palavras-chave: Educação escolar, Teoria pedagógica, Transmissão de conhecimentos, Pedagogia histórico-crítica.

\section{KNOWLEDGE TRANSMISSION IN DEBATE: MIGHT CRITICAL-HISTORICAL PEDAGOGY REHABILITATE TRADITIONAL TEACHING METHODS?}

\begin{abstract}
The article seeks to contribute to the debate regarding the defense of the transmission of the scientific, artistic and philosophical knowledge claimed by historical-critical pedagogy in the current political-cultural context of obscurantism and attacks on reason. Based on theoretical-conceptual

\footnotetext{
${ }^{1}$ Departamento de Psicologia, Universidade Estadual Paulista (UNESP). Bauru, SP, BR. <juliana.pasqualini@unesp.br>

${ }^{2}$ Departamento de Ciências da Saúde, Universidade Estadual de Santa Cruz (UESC). Ilhéus, BA, BR.

<nicolalavoura@gmail.com>
} 
investigation of bibliographic nature, it explores the differences between the critical-historical proposition and traditional teaching methods, arguing that the divergences with non-directive pedagogies do not grant a rehabilitation of traditional pedagogy, marked by the prevalence of inductive method, by verbalism and by the a-critical apprehension of the relationship between school and society. It is concluded that critical-historical pedagogy preserves the principle of the transmission of knowledge for every student, but, once it is based on another conception of knowledge, it is carried out from another method and subordinates itself to a different purpose, that principle is requalified, pursuing praxis. Finally, the understanding of the transmission of knowledge as a principle of ontological - and not didactic or operational - nature within the educational process is postulated.

Keywords: School education, Pedagogical theory, Knowledge transmission, Critical-historical pedagogy.

\section{LA TRANSMISIÓN DEL CONOCIMIENTO EN DEBATE: ¿ESTARIA LA PEDAGOGÍA HISTÓRICO- CRÍTICA REHABILITANDO LA ENSEÑANZA TRADICIONAL?}

RESUMEN: El artículo intenta profundizar el debate sobre la defensa de la transmisión del conocimiento científico, artístico y filosófico reivindicado por la pedagogía histórico-crítica en el contexto político y cultural actual del oscurantismo y los ataques a la razón. Basado en una investigación teórico conceptual de tipo bibliográfico, explora las diferencias entre la proposición histórico-crítica y los métodos de enseñanza tradicionales, argumentando que la lucha contra las pedagogías no directivas no otorga un movimiento para la rehabilitación de la pedagogía tradicional, marcada por la prevalencia del método inductivo, verbalismo y aprehensión acrítica de la relación escuela-sociedad. Se concluye que la pedagogía histórico-crítica conserva el principio de la transmisión del conocimiento a todos, pero, dado que se basa en otra concepción del conocimiento, se realiza a partir de otro método y está subordinado a otro propósito, este principio es recalificado, vislumbrando la praxis. Finalmente, se postula entender la transmisión de conocimiento como un principio ontológico, y no didáctico u operativo, del proceso educativo.

Palabras clave: Educación escolar. Teoría pedagógica. Método. Transmisión de conocimientos. Pedagogía histórico-crítica. 


\section{INTRODUÇÃO}

"A escola e seus mestres representam hoje, para muitos, um rival a abater e a suplantar. As coisas não foram diferentes em todo o decurso do s. XIX, sempre que poderes conservadores

temiam a aç̧ão do ensino público"

(SNYDERS, 1974, p. 15).

O debate que o coletivo de pesquisadores vinculados ao projeto de edificação da pedagogia histórico-crítica tem travado no campo educacional vem centrando forças na crítica às chamadas perspectivas ativas (ou não-diretivas) na pedagogia, herdeiras do escolanovismo.

Ante o cenário de esvaziamento de conhecimentos elaborados e sistematizados dos currículos escolares forjado pelo projeto neoliberal de sociedade em pleno curso, cuja máxima expressão factual pode ser constatada em meio à onda crescente do obscurantismo face à razão ${ }^{3}$, tem sido central a defesa da transmissão-assimilação de conteúdos científicos, artísticos e filosóficos como tarefa precípua da escola que interessa à população que vive do próprio trabalho.

Nessa oportunidade, nosso objetivo é explorar as diferenças entre o método históricocrítico da pedagogia e o ensino tradicional, alertando que o esforço de afastamento das pedagogias ativas não significa (re)aproximarmo-nos das assim chamadas práticas educativas tradicionais. Buscaremos evidenciar que, ainda que reconheçamos o aspecto revolucionário contido no princípio da transmissão do conhecimento que subjaz a pedagogia tradicional (SAVIANI, 2012), seu método, sua compreensão a-histórica e acrítica das relações entre escola e sociedade e seu consequente telos pedagógico mostram-se claramente divergentes dos princípios e proposições da perspectiva históricocrítica.

Queremos resgatar o fato de que, ao formular originalmente a proposta de uma pedagogia histórico-crítica, Dermeval Saviani (2012) demarcou a contraposição também aos métodos tradicionais da pedagogia. Sendo assim, respondendo de forma abertamente negativa à pergunta que intitula o presente artigo, trataremos de evidenciar que em vista de seus fundamentos e de seu método de ensino, a pedagogia tradicional promove um tipo de formação na qual prevalece o pensamento empírico, ao passo que a pedagogia histórico-crítica vislumbra o desenvolvimento do pensamento teórico e da consciência filosófica (DAVYDOV, 2008; KOPNIN, 1978; SAVIANI, 2013a). Ao mesmo tempo, reafirmaremos que o reconhecimento da diferença entre pedagogia tradicional e pedagogia históricocrítica não nos autoriza a aceitar o "presente de grego" das pedagogias do aprender a aprender.

\footnotetext{
3 A problemática do conhecimento e, notadamente, a defesa intransigente da socialização do saber sistematizado nas suas formas mais desenvolvidas, posição inequivocamente assumida pela pedagogia histórico-crítica desde a gênese de sua formulação, nunca se apresentou como tão necessária e vital na atual conjuntura ideo-política de ascensão de governos de extrema-direita, como agora no caso brasileiro, constantemente tendo-se o presidente, seus chefes de governo e respectivos ministros de Estado destilando falsas e infundadas afirmações acerca do trabalho educativo realizado no interior das escolas de educação básica e do ensino superior em nosso país, cujo pretexto de um suposto combate à "ideologização do ensino", à "doutrinação da esquerda" e a defesa de uma "escola sem partido", esconde-se a finalidade de esvaziamento do conhecimento elaborado e o confisco do direito de todos ao acesso à ciência e à verdade. Ademais, "sua real finalidade é a criação de um ambiente de censura ideológica, ética e política dos professores, dos currículos e dos materiais pedagógicos, de maneira a se submeter a escola pública aos ditames das mais reacionárias e irracionalistas concepções de mundo existente na sociedade contemporânea" (DUARTE, 2018, p. 140).
} 
Este artigo sustenta essa tese com base nos resultados de uma investigação teóricoconceitual de tipo bibliográfica com procedimento de análise de revisão de literatura (GIL, 2008). As fontes de análise constituíram-se por literatura bibliográfica cuja centralidade temática está circunscrita ao objeto de análise aqui investigado, delimitando-se as seguintes categorias analíticas, com vistas ao estudo comparativo entre as proposições da pedagogia histórico-crítica e da pedagogia tradicional: finalidade da educação escolar; relação escola-sociedade; método de ensino, concepção de conhecimento; conceito de transmissão do conhecimento.

Uma vez delimitado o material de pesquisa, abaixo elencado, nos orientamos à análise do mesmo pelos seguintes procedimentos, próprios à investigação bibliográfica (TRIVIÑOS, 2009): $i$ compreensão dos significados dos conceitos apresentados e suas correlações, tendo em vista a formulação de uma síntese primária em relação ao material em análise; ii-identificação da(s) ideia(s) diretriz(es), isto é, das asserções, e das ideias explicativas às mesmas (razões) presentes nas fontes; iiidiferenciação e análise comparativa das ideias diretrizes entre si, a fim de determinar a importância relativa de cada uma delas no conjunto das produções de cada autor em análise; e, $i v$ - procedeu-se à operação de síntese, isto é, integração racional dos dados descobertos no conjunto bibliográfico analisado sobre o tema em investigação, retomando-se a problemática e os objetivos da pesquisa.

A exposição dos resultados estrutura-se em três momentos fundamentais que correspondem a objetivos específicos que conduziram a investigação. Primeiramente orientamo-nos pelo objetivo de proceder ao resgate das proposições de Dermeval Saviani (2012) na obra Escola e Democracia, quando postula o caráter revolucionário da pedagogia tradicional perante o caráter reacionário da pedagogia nova, ressaltando a dimensão histórico-filosófica e política da pedagogia tradicional.

Já o segundo movimento do texto responde à finalidade de contextualização e apresentação do método tradicional da pedagogia em correspondência à lógica formal do desenvolvimento da forma de apreensão do conhecimento, tendo como centro da análise o pensamento de J. F. Herbart. Essa tarefa é realizada a partir da referência a textos clássicos de historiadores e analistas da pedagogia, como Brubacher (1961), Cambi (1999), Hilgenheger (1993), Larroyo (1970), Saviani (2012), Snyders (1974) e Suchodolski (2010), bem como ideias centrais da chamada Escola de Vigotski no que se refere à relação entre ensino e desenvolvimento psíquico.

Por fim, passamos ao exame de alguns fundamentos da pedagogia histórico-crítica, incorporando as contribuições de Davydov (2008), Ilyenkov (2008), Kopnin (1978), Marx (2011), Vigotski (2001, 2012) e do próprio Saviani (2012, 2013a, 2013b), visando defender uma posição teórico-metodológica que pode ser assim sintetizada: a pedagogia histórico-crítica conserva da pedagogia tradicional o princípio da transmissão do conhecimento para todos, mas, na medida em que se baseia em outra concep̧̧ão de conhecimento, subordina-se a outra finalidade - pedagógica e política - e se realiza a partir de outro método, tal princípio é requalificado, vislumbrando a práxis que transforma a realidade social.

Como preâmbulo ao desenvolvimento da argumentação, faz-se necessário estabelecer a distinção entre as proposições das pedagogias tradicionais e aquilo que ficou conhecido como "ensino tradicional”. Saviani (2012, p. 42) explica que o assim chamado ensino tradicional "[...] constituiu-se após a Revolução Industrial e implantou-se nos chamados sistemas nacionais de ensino, configurando 
amplas redes oficiais criadas a partir de meados do século XIX”, estruturando-se, fundamentalmente, sobre o método pedagógico expositivo.

$\mathrm{O}$ autor pondera que "a crítica escolanovista atingiu não tanto o método tradicional mas a forma como esse método se cristalizou na prática pedagógica, tornando-se mecânico, repetitivo, desvinculado das razões e finalidades que o justificavam [...]" (SAVIANI, 2012, p. 53), ou seja, as críticas "atingiram o método tradicional não em si mesmo mas a sua aplicação mecânica cristalizada na rotina burocrática do funcionamento das escolas”. N’O Manifesto dos Pioneiros da Educação Nova, de 1932, lê-se, justamente, que a nova concepção de escola que ali se advoga "[...] é uma reação contra as tendências exclusivamente passivas, intelectualistas e verbalistas da escola tradicional" (AZEVEDO et al, 2006, p. 196).

No presente texto, buscaremos dialogar com essa amplitude de significados associados ao termo tradicional na seara educacional, mas tomaremos propriamente como objeto de crítica a proposição metodológica da pedagogia tradicional, destacando, a partir da leitura histórico-crítica, os seguintes aspectos: a apreensão acrítica e a-histórica da relação escola-sociedade; a prevalência do método indutivo; e a concepção de ensino como apresentação do conhecimento pelo professor.

\section{A POSITIVIDADE DA PEDAGOGIA TRADICIONAL EM PERSPECTIVA HISTÓRICO- FILOSÓFICA E SEU SIGNIFICADO POLÍTICO}

Na obra Escola e Democracia, Saviani (2012, p. 59) formulou a polêmica tese "do caráter revolucionário da pedagogia da essência (pedagogia tradicional) e do caráter reacionário da pedagogia da existência (pedagogia nova)". Lançando mão da "teoria da curvatura da vara", o autor, segundo suas próprias palavras, buscou “[...] polemizar, abalar, desinstalar, inquietar, fazer pensar" (p. 60), veiculando uma propositura antitética às ideias então dominantes no meio educacional, nas quais a pedagogia tradicional era tida como portadora de todos os vícios e nenhuma virtude e, inversamente, a pedagogia nova como portadora de todas as virtudes e nenhum vício.

No contexto do embate entre as chamadas pedagogias ativas e a escola tradicional, a análise de Saviani (2012) localiza o referido caráter revolucionário da pedagogia tradicional em dois aspectos fundamentais, quais sejam, o igualitarismo e a primaz̧ia dos conteúdos, isto é, a reivindicada importância da transmissão de conhecimentos.

A escola tradicional propunha-se, afinal, a transmitir a todo estudante os conhecimentos obtidos pela ciência, sistematizados e incorporados ao acervo cultural da humanidade. Ambos os aspectos destacados por Saviani (2012) se vinculam ao fato de a pedagogia tradicional caracterizar-se como pedagogia da essência. Saviani (2012) argumenta que a pedagogia tradicional é uma pedagogia que se funda em uma concepção filosófica essencialista, a qual demarca a defesa intransigente da igualdade essencial entre os homens, ao passo que a pedagogia nova se funda numa concepção filosófica que privilegia a existência sobre a essência.

\footnotetext{
4 Saviani (2012, p. 37), explica que a teoria da curvatura da vara teria sido enunciada por Lênin ao ser criticado por assumir posições extremistas e radicais, ponderando que "quando a vara está torta, ela fica curva de um lado e se você quiser endireitá-la, não basta colocá-la na posição correta. É preciso curvá-la para o lado oposto”. 
Para compreender a assertiva de Saviani (2012), é necessário que nos detenhamos sobre a conceituação da pedagogia da essência e da pedagogia da existência, recorrendo ao pensamento do educador polonês Bogdan Suchodolski. Na obra A pedagogia e as grandes correntes filosóficas, Suchodolski (2010) postula que o conflito central do pensamento pedagógico na história da educação ocidental se dá entre as dimensões da essência e da existência. $\mathrm{O}$ autor pontua a existência de variadas tentativas de classificação das diversas correntes do pensamento pedagógico moderno e argumenta que é preciso efetuar tal análise de modo que se superem critérios advindos de "princípios exteriores ao processo histórico" (p. 89), buscando "revelar as contradições internas que se tornaram ponto de partida da luta de concepções” (p. 89):

Ao considerar a questão deste modo pensamos poder penetrar no aspecto profundo do processo de desenvolvimento do pensamento pedagógico moderno e evidenciar as lutas crescentes que ocorrem entre o que se poderá designar a pedagogia da existência e a pedagogia da essência. [...] Esta querela filosófica não respeita unicamente os problemas metafísicos abstratos, toca o próprio homem. A filosofia do homem é elaborada de modo totalmente diverso, conforme se tomam para ponto de partida a filosofia da essência ou da existência. Esta diferença conduz-nos justamente ao próprio coração das querelas pedagógicas (SUCHODOLSKY, 2010, p. 89).

Como explica Mafra (2010, p. 45), a formulação de Suchodoslki considera que "a primeira pedagogia [da essência], fundada numa matriz idealista, toma o ser humano como deve ser; a segunda [da existência], assentada numa visão empírica do homem, analisa-o a partir do que ele realmente é”. A querela entre a pedagogia da essência e a pedagogia da existência teria sua gênese durante o Renascimento, prosseguindo no decurso do século XVII. A pedagogia da essência inicialmente teria em Platão e posteriormente em São Tomás de Aquino seus portos teóricos:

É a corrente mais antiga do pensamento educacional que, a despeito das críticas e embates provenientes da pedagogia da existência, não se extinguiu, chegando com bastante vitalidade aos nossos dias. E isso não se reflete apenas no campo das ideias, mas, com mais ênfase ainda, nas práticas educativas, considerando que o ser humano ideal continua a ser, arriscaríamos dizer, o horizonte a partir do qual se desenvolve a maior parte das ações pedagógicas (MAFRA, 2010, p. 45-46).

Saviani (2012) explica que concepções essencialistas se fizeram presentes desde a Antiguidade grega, então restritas aos homens livres (vez que os escravos não eram considerados seres humanos), recebendo uma inovação na Idade Média ao articular a essência humana com a criação divina. Sendo as pessoas criadas segundo uma essência predeterminada, seus destinos eram tidos como previamente definidos, "consequentemente, a diferenciação da sociedade entre senhores e servos já estava marcada pela própria concepção que se tinha da essência humana. Então a essência humana justificava as diferenças” (p. 38).

$\mathrm{Na}$ época moderna, a filosofia da essência adquire novo conteúdo, de caráter igualitário, atuando no sentido da ruptura do modo de produção feudal e gestação do modo de produção capitalista, "quando, no campo da vida social e política, se puseram em dúvida direitos até então 
imutáveis do clero e da aristocracia feudal [...]” (SUCHODOLSKI, 2010, p. 92). Explica Saviani (2012, p. 38):

[...] a burguesia, classe em ascensão, vai manifestar-se como uma classe revolucionária, e, enquanto classe revolucionária, vai advogar a filosofia da essência como um suporte para a defesa da igualdade dos homens como um todo e é justamente daí que ela aciona as críticas à nobreza e ao clero (grifos nossos).

O combate aos privilégios assegurados pelo nascimento e à dominação pela nobreza e pelo clero marca, portanto, o contexto histórico de emergência e consolidação de uma nova sociedade, baseada na igualdade (formal) e na ordem (formalmente) democrática. Nesse contexto, o papel da escola e da socialização de instrumentos culturais torna-se relevante: "escolarizar todos os homens era condição para converter os servos em cidadãos” (SAVIANI, 2012, p. 40).

Contudo, uma vez estabelecido o modo de produção capitalista e a dominação da massa trabalhadora pela burguesia mediante a expropriação dos meios de produção daquela, o igualitarismo converte-se em obstáculo à manutenção da nova ordem. A filosofia essencialista passa, logo, a ser combatida pela própria classe que dela lançou mão em seu momento revolucionário. A nova sociedade, que tem a liberdade e a igualdade como princípios formais, não se mostra capaz de concretizar igualdade e liberdade substantivas entre os homens, razão pela qual se carece de um novo ideário que possa legitimar a desigualdade e a dominação que se perpetuam sob novas condições. A pedagogia da existência, segundo Saviani (2012, p. 41), vem justamente afirmar que:

[...] os homens são essencialmente diferentes, e nós temos de respeitar as diferenças entre os homens. Então há aqueles que têm mais capacidade e aqueles que têm menos capacidade; há aqueles que aprendem mais devagar; há aqueles que se interessam por isso e os que se interessam por aquilo.

De acordo com Suchodolski (2010, p. 98-99), a pedagogia da essência tornou-se objeto de ataque em meados do século XVII, ataque esse "perfeitamente consciente" e "fértil em repercussões". Segundo sua análise, "[...] a pedagogia de Rousseau foi a primeira tentativa radical e apaixonada de oposição fundamental à pedagogia da essência e de criação de perspectivas para uma pedagogia da existência”. Mafra (2010, p. 46-47) também contribui para esta compreensão histórica:

É na Renascença que aparecem as primeiras manifestações da pedagogia da existência. As radicais transformações ocorridas nessa época, sobretudo pela decadência do sistema feudal e enfraquecimento do poder católico, no início da modernidade, introduziram questionamentos profundos às tradições. $\mathrm{O}$ deslocamento para um olhar antropocêntrico da vida, bem como a instauração de um novo sentido de indivíduo, em certos contextos europeus, criaram possibilidades éticas de se pensar o ser humano pragmaticamente, isto é, em seu cotidiano concreto. [...] Foi a partir das diferentes contribuições filosóficas de Kierkegaard (1813-1855), Stirner (1806-1856) e Nietzsche (1844-1900), que a pedagogia da existência começou a tomar corpo. Fortaleceu-se com as teorias evolucionistas de Charles Darwin (1809- 1882), no campo do desenvolvimento da natureza e de Herbert Spencer (1820-1903), a respeito do desenvolvimento social. [...] De acordo com Suchodolski, Rousseau (1712-1778) foi o primeiro 
autor a radicalizar as críticas à pedagogia da essência, criando assim 'perspectivas para uma pedagogia da existência (p. 33)'.

Stanley Hall (1846-1924), Édouart Claparède (1873-1940), John Dewey (1859-1952) e JeanOvide Decroly (1871-1932) são representantes da pedagogia da existência que acaba por se consolidar, para além de revolta contra a pedagogia da essência, em “[...] programa geral de ação, um sistema determinado de investigações, um conjunto de métodos e aquisições na via do conhecimento". (MAFRA, 2010, p. 52). Saviani (2012) destaca alguns princípios que subjazem a essa perspectiva: as pessoas são essencialmente diferentes, pois cada indivíduo é único, e a integração ao grupo social é fundamentalmente uma questão de aceitação: cabe à educação contribuir para “[...] a constituição de uma sociedade cujos membros, não importam as diferenças de quaisquer tipos, se aceitem mutuamente e se respeitem na sua individualidade específica." Com a consolidação da pedagogia da existência, "forja-se, então, uma pedagogia que advoga um tratamento diferencial a partir da 'descoberta' das diferenças individuais" (SAVIANI, 2012, p. 8).

Em nome do reconhecimento e da aceitação das diferenças, a perspectiva igualitarista é preterida, ou denegada. Na análise de Saviani (2012), a consequência política da passagem histórica de uma concepção pedagógica igualitarista para uma pedagogia das diferenças não é outra coisa senão a justificação de privilégios e a naturalização da desigualdade.

Isto posto, é importante destacar que a pedagogia histórico-crítica se apresenta como proposição para além das pedagogias da essência e da existência. Sua formulação tem, em sua gênese, uma análise crítica que identifica elementos de positividade da pedagogia tradicional, entendida como pedagogia da essência, os quais residem fundamentalmente no princípio da transmissão do conhecimento (e da igualdade entre os homens) nela contido. Afirma Saviani (2012, p. 41):

A pedagogia da essência não deixa de ter um papel revolucionário, pois, ao defender a igualdade essencial entre os homens, continua sendo uma bandeira que caminha na direção da eliminação daqueles privilégios que impedem a realização de parcela considerável dos homens (SAVIANI, 2012, p. 41).

É decisivo compreender, contudo, que tal reconhecimento não significa qualificar a pedagogia tradicional como uma pedagogia revolucionária. Assim como o escolanovismo, a pedagogia da essência (ou pedagogia tradicional) caracteriza-se como teoria não-crítica da educação, por tomar a educação escolar como "redentora da sociedade"; assim, mesmo ao tratar do princípio da igualdade, ela o faz apenas em termos formais. Justamente com base nesta análise é que Saviani (2012, p. 52) anuncia a necessidade de superação tanto dos métodos novos quanto dos tradicionais:

Uma pedagogia revolucionária centra-se, pois, na igualdade essencial entre os homens. Entende, porém, a igualdade em termos reais e não apenas formais. Busca, pois, converter-se, articulando-se com as forças emergentes da sociedade, em instrumento a serviço da instauração de uma sociedade igualitária. Para isso a pedagogia revolucionária, longe de secundarizar os conhecimentos descuidando de sua transmissão, considera a difusão de conteúdos, vivos e atualizados, uma das tarefas primordiais do processo educativo em geral e da escola em particular. 
Vemos nesse excerto que, ao vislumbrar uma pedagogia revolucionária, Saviani (2012) conserva o princípio da socialização do conhecimento a serviço da instauração de uma sociedade igualitária, mas retifica que a igualdade deve ser considerada em termos reais e não apenas formais. A teoria é clara em sua formulação: pedagogias que secundarizam o conhecimento em nome de um suposto respeito às diferenças colocam-se a serviço da manutenção da ordem dos privilégios, na medida em que sonegam a grupos e comunidades o acesso ao saber que se utiliza para dominá-los, seja por obnubilar a realidade, mantendo-a ininteligível, seja por despotencializar a ação dos sujeitos sociais ao lhe subtrair instrumentos conceituais/teóricos. Eis o que leva Saviani (2012) a salvaguardar os princípios da transmissão e da primazia do conhecimento da pedagogia tradicional, que não casualmente foram abandonados e atacados no movimento de recomposição da hegemonia burguesa.

Em George Snyders, educador marxista que é tomado por Saviani como uma das principais influências na elaboração da pedagogia histórico-crítica (SAVIANI, 2013b), encontramos elementos importantes para compreender a positividade do ensino tradicional em perspectiva histórico-filosófica e o sentido dos ataques e críticas - muitas vezes infundadas e distorcidas - proferidas pelos ideólogos dos métodos novos. Carvalho (1999, p. 155-156) assim sintetiza a análise desse autor acerca dos aspectos positivos ou válidos da escola tradicional:

\footnotetext{
- A necessidade da Educação: de que o mundo imediato, empírico, cotidiano, por si só não forma o aluno, não possibilita a apreensão do real.

- No processo de ensino-aprendizagem há a necessidade do professor como guia, como orientador. A criança necessita de apoio, de orientação, para formar uma disciplina, um autodomínio, para poder ter possibilidade de apreender o real e sobre ele atuar.

- Há um reconhecimento da validade de modelos, da primazia dos modelos, ou do conhecimento, na educação.
}

Snyders (1974) considera que um dos fundamentos da educação tradicional era conduzir os alunos a se confrontarem com os grandes modelos da história, ou seja, terem contato com as grandes realizações da humanidade:

Ponhamos os novos em face das grandes personagens, dos grandes artistas singulares. Poderão assim ouvir a sua voz, reconhecer os seus tormentos e é possível que se sintam possuídos do desejo de irem também até o fundo de si mesmos (SNYDERS, 1974, p. 16-17).

Da confrontação com os grandes modelos da história, Snyders (1974) destaca cinco elementos fundamentais: i) a aproximação do aluno ao modelo exige dele um papel ativo (ao contrário da ideia imputada de um ensino passivo); ii) a apropriação do modelo é condição para o afloramento da originalidade do aluno, ou seja, o despertar de sua própria individualidade (o que está na contramão das acusações de falta de autonomia e liberdade); iii) o contato com os modelos gera no aluno um sentido de encantamento, alegria e plenitude pelo conhecimento (em que pese a caracterização de uma escola sem sentido); iv) o professor assume papel indispensável como mestre que orienta o aluno para que se confronte com o modelo em condições favoráveis e exitosas, uma vez que não há ascensão sem guia e; por fim, v) a finalidade de todo o ensino com base na confrontação de modelos é o aluno mais senhor de si mesmo, obtendo o domínio de si mesmo e despertando a consciência. 
A conclusão a que chega Snyders (1974) é que não obstante as estagnações, as deficiências, as falhas e mesmo a falência do ensino tradicional, não se pode ignorar ou negar os valores de verdade e os princípios de realidade que tal ensino era portador, sobretudo por meio dos ataques e das caricaturas desferidos pelos agentes de disseminação dos métodos novos. Se é verdade que essa intencionalidade pedagógica do ensino tradicional não se concretizou, isso se deve às contradições históricas em que se desenvolvia - e se desenvolve - a educação na sociedade de classes:

A escola surge como um antídoto à ignorância, logo, um instrumento para equacionar o problema da marginalidade. Seu papel é difundir a instrução, transmitir os conhecimentos acumulados pela humanidade e sistematizados logicamente. O mestre-escola será o artífice dessa grande obra. A escola se organiza, pois, como uma agência centrada no professor, o qual transmite, segundo uma gradação lógica, o acervo cultural aos alunos. A estes cabe assimilar os conhecimentos que lhes são transmitidos.

À teoria pedagógica acima indicada correspondia determinada maneira de organizar a escola. Como as iniciativas cabiam ao professor, o essencial era contar com um professor razoavelmente bem preparado. Assim, as escolas eram organizadas na forma de classes, cada uma contando com um professor que expunha as lições que os alunos seguiam atentamente e aplicava os exercícios que os alunos deveriam realizar disciplinadamente.

Ao entusiasmo dos primeiros tempos suscitado pelo tipo de escola acima descrito de forma simplificada, sucedeu progressivamente uma crescente decepção. A referida escola, além de não conseguir realizar seu desiderato de universalização (nem todos nela ingressavam e mesmo os que ingressavam nem sempre eram bem sucedidos) ainda teve de curvar-se ante o fato de que nem todos os bem-sucedidos se ajustavam ao tipo de sociedade que se queria consolidar. Começaram, então, a se avolumar as críticas a essa teoria da educação e a essa escola que passa a ser chamada de escola tradicional (SAVIANI, 2012, p. 17).

É primordial apreender que a pedagogia tradicional concebia a educação de maneira autônoma perante as relações sociais vigentes, atribuindo à escola a tarefa de correção do problema da marginalidade, tomando acriticamente a relação de determinação existente entre escola e sociedade, o que a caracteriza como uma pedagogia não-crítica. Em Escola e Democracia, Saviani (2012) focaliza essa característica como convergência entre pedagogia tradicional e pedagogia nova: em ambos os casos está pressuposta uma autonomização da pedagogia em relação à sociedade, sendo professor e alunos considerados em termos individuais e como habitantes de uma realidade harmônica - e não agentes sociais de uma realidade fundamentalmente contraditória.

Ao formular a proposta da pedagogia histórico-crítica, Saviani (2012) trava debate com os métodos tradicionais e novos da pedagogia, vislumbrando um método pedagógico que supere a ambos - compreendendo superação no sentido dialético, ou seja, envolvendo simultaneamente o ato de negação e o ato de incorporação de aspectos válidos (elementos de verdade). Em sua avaliação, os dois métodos mostram-se equivocados respectivamente ao identificar o ensino com a mera apresentação de conhecimentos ou preconizar sua substituição pela (pseudo) produção de conhecimentos. Para aprofundamento dessa discussão, procederemos à apresentação do que se propunha a pedagogia tradicional em termos metodológicos. 


\section{O MÉTODO DA PEDAGOGIA TRADICIONAL: OS PASSOS FORMAIS HERBARTIANOS}

Do conjunto de concepções que integram a pedagogia tradicional, é o método derivado do pensamento do educador alemão Johann Friedrich Herbart (1776-1841) que Dermeval Saviani (2012) toma como referência para o debate crítico com o método tradicional da pedagogia. $\mathrm{Na}$ obra Escola $e$ Democracia as limitações dos cinco passos formais do sistema de instrução educativa herbartiano serviram como contraponto ${ }^{5}$ para a formulação do método histórico-crítico.

"Herbart pertence aos grandes filósofos tributários de Kant” (LARROYO, 1970, p. 683). Segundo Cambi (1999, p. 431), historiador da pedagogia, Herbart elaborou um sistema filosófico de orientação nitidamente antirromântica, inspirado no realismo metafísico, apoiando-se no pensamento de Kant - recorrendo à concepção kantiana do papel criador da razão segundo esquemas estabelecidos previamente, que o mesmo denominou de formas inatas de sensibilidade, ou razão pura - e de Leibniz. Afirma o autor:

Com Herbart emerge, com plena clareza, um empenho da pedagogia de constituir-se como 'ciência', ainda que como ciência filosófica, e portanto o início de uma pesquisa epistemológica em pedagogia. O outro caráter fundamental dessa concepção educativa está ligado ao profundo humanismo que a inspira. O objetivo final da pedagogia permanece o de formar o homem, e formá-lo como totalidade harmônica e como pessoa responsável, mostrando a importância do 'caráter' no âmbito da educação moral e da educação estética (CAMBI, 1999, p. 431).

Em suas obras, ainda conforme Cambi (1999), Herbart defronta-se com as várias expressões do pensamento pedagógico moderno, asseverando que "os idealistas afirmaram a existência de uma liberdade transcendental, com a qual vêm porém negar todo processo educativo verdadeiro, enquanto eliminam seu caráter de 'tarefa' e de 'esforço". Cambi (1999, p. 436) informa que "o herbatismo difundiu-se sobretudo na Alemanha, nos Estados Unidos e na Itália, pondo no centro do problema educativo o papel do professor e um ordenamento preciso dos processos de instrução".

Decerto, a efetiva análise de um método supõe que nos interroguemos acerca das finalidades às quais se orienta, ou seja, a intencionalidade que condiciona e guia o percurso metodológico. Para Herbart, o fim supremo da educação é a virtude, a força moral do caráter. Tem destaque na perspectiva herbartiana o problema moral, colocando para a pedagogia o horizonte de conformar o ser humano a um modo de vida regido por fins moralmente valiosos. Conforme Larroyo (1970, p. 665), para Herbart, “a tarefa da educação reside em formar o caráter, que na luta da vida deve manter-se inquebrantável, e não precisamente pela força da ação externa sobre a pessoa, mas graças a uma resoluta e clara atitude moral".

Larroyo (1970) aponta, ainda, as cinco virtudes que, segundo o pensamento herbartiano, devem orientar a formação humana: a liberdade interior resoluta e com prazenteira inclinação para desejar o bem, como fundamento para uma sociedade de homens livres; a plenitude de valores que propende para a realização de objetivos nobres, como fundamento para um sistema de bens culturais; a benevolência, a justiça e a equidade, que correspondem, respectivamente, a querer o bem do próximo, dar a cada um o que é seu e garantir recompensa e reparação adequada, na perspectiva de uma comunidade jurídica

${ }^{5}$ Juntamente com os passos do método de J. Dewey (1859-1952).

Educação em Revista|Belo Horizonte|v.36|e221954|2020 
articulada a um sistema de ideais, em um regime de recompensas e salários equitativos. Em suma, "virtude é o nome que convém à totalidade do fim pedagógico" (HERBART n/d apud LARROYO, 1970, p. 665). Destacamos, aqui, a perspectiva de formação de um sentimento de equidade nas crianças, o que só faz evidenciar a afirmação anterior do caráter não-crítico desta pedagogia, uma vez que tal intencionalidade não leva em consideração as determinações e condicionamentos da prática educativa, esta que ocorre no interior da prática social, idealisticamente elevando a educação à condição de redentora da moralidade humana.

Como explica Hilgenheger (1993), a educação tem, para Herbart, a tarefa paradoxal de levar o aluno a agir de maneira autônoma exercendo sobre ele influências determinadas desde o exterior. Essa perspectiva pode ser observada quando, referindo-se a um pupilo do qual foi preceptor, afirmou:

[...] a única oportunidade que se poderia ainda jogar para formar seu caráter seria seu entendimento enquanto capacidade passiva de apreender aquilo que lhe é apresentado lentamente (vagarosamente) após tê-lo bem preparado e a esperança de que esta fraca centelha fará um dia surgir a reflexão autônoma ativa e a aspiração de viver conforme os seus ensinamentos (HERBART, 1982a, p. 23 apud HILGENHEGER, 1993, p.4).

A instrução é, para o pensador, condição para a educação, mas a ela subordina-se, e seu método pedagógico levaria os alunos a receberem não somente uma instrução, mas, igualmente, uma educação (HILGENHEGER, 1993). Em Herbart, a instrução tem um fim educativo, de modo que a verdadeira instrução é instrução educativa, que forma a vontade e modela o caráter: "o caráter moral, finalidade da educação, alcança-se pela instrução, pela disciplina e pelo governo" (LARROYO, 1970, p. 666).

Larroyo (1970) sintetiza as premissas da teoria da disciplina e do governo escolar enlaçadas à instrução educativa. Segundo sua formulação, a pedagogia de Herbart preconiza que o governo tem seu papel especialmente nos anos da primeira infância e "[...] nos períodos de particular perigo" (p. 670), mas tem de desaparecer tão logo seja possível, de modo a dar ensejo à espontaneidade, à invenção, à ousadia. A disciplina, cujas regras podem ser ocasionais ou contínuas, faz-se necessária por seus efeitos imediatos, ao passo que a instrução opera de forma mediata, modificando as ideias e formando novas representações, que por sua vez determinam o comportamento. Eis a chave para compreender a possibilidade de que a Educação atue na formação do caráter: "a instrução pode criar novas representações, e as massas mais fortes de representações determinam nosso agir [...]" (p. 666).

Nesse percurso formativo que intenciona a acolhida de novas representações na consciência, o interesse do aluno tem papel decisivo: “[...] o meio de conseguir esta instrução educativa é produzir no espírito da criança um interesse múltiplo" (p. 667). Diferentemente da ideia que prevalece no ideário pedagógico contemporâneo em torno do ensino tradicional, a formulação do sistema de instrução educativa " [...] tinha a experiência do aluno como função central e o interesse do aluno, traço de sua atividade mental própria, não apenas como fim, mas como o meio mais importante da instrução educativa" (HILGENHEGER, 1993). Herbart chegou a afirmar que o interesse é a 'palavra mágica' da Pedagogia: "[...] o interesse exclui a violência, suaviza o esforço até quase suprimi-lo. Tudo está perdido se desde o princípio se converte o estudo numa espécie de tormento" (HERBART n/d apud LARROYO, 1970, p. 667). Sua visão é a de que o interesse ativa a atenção, e esta, posta em 
movimento, pode ser aplicada a um objeto para captá-lo fielmente, em sua totalidade (apreensão analítica), e/ou estabelecer associações entre diversos objetos ou elementos (consciência sintetizadora).

Tendo esclarecido a finalidade que guia a educação e pontuado o papel do governo, da disciplina e do interesse no processo educativo, podemos nos deter na dimensão propriamente metodológica da instrução educativa de Herbart. O ordenamento preciso dos processos de instrução, conforme Larroyo (1970) resulta, no pensamento herbatiano, da combinação entre movimentos de apreensão analítica e consciência sintetizadora, expressando-se em passos formais, que representariam a forma geral pela qual o educando pode apropriar-se das diversas matérias de ensino. A formulação original do método da instrução educativa de Herbart prevê quatro passos: 1) etapa da clareza ou da demonstração do objeto; 2) etapa da associação ou comparação; 3) etapa da sistematização ou generalização; 4) etapa do método ou aplicação. Tal formulação foi veiculada e desenvolvida pelos discípulos de Herbart, nomeadamente Tuiskson Ziller (1817-1882), Frederico Guillerme Dörpfeld (1824-1893) e Wilhelm Rein (1847-1929), tendo sido modificada pelo último para a sequência de cinco passos formais que se tornou amplamente conhecida na Pedagogia ${ }^{6}$, como explica Larroyo (1970). Segundo a proposição tornada célebre, cada lição deveria atender aos seguintes passos: 1) preparação; 2) apresentação; 3) assimilação (comparação/ associação); 4) generalização (consideração); 5) aplicação.

O escolanovista John S. Brubacher ${ }^{7}$ (1961, p. 3) assim detalha os passos do chamado método herbartiano:

No passo de 'preparação', o professor recorda alguma coisa que os alunos já sabem ou com que estão familiarizados. No segundo passo o professor 'apresenta' a nova matéria que deve ser aprendida no curso da lição. No passo seguinte, 'compara' a matéria nova com a matéria antiga, de tal maneira que o aluno seja capaz de assimilar o novo em termos do velho. Alguns autores, com efeito, chamam a este terceiro passo 'assimilação', de preferência a comparação. O passo seguinte consiste na apresentação de um certo número de casos semelhantes ao que se acaba de examinar. Tal similaridade, em si mesma, possibilita ao professor 'generalizar' e enunciar uma regra ou princípio, que se aplica a todos os casos iguais. Quando isso se torna claro aos alunos, o professor está pronto para o último passo, que consiste em aduzir outros casos, e dizer ao aluno que faça por si mesmo a 'aplicação' da regra ou princípio. O passo da aplicação geralmente coincide com o de atribuir ao aluno tarefas para realizar em casa.

Vale observar que o momento da preparação se relaciona a um esforço de promover o interesse do aluno pelo tópico em questão, mediante o estabelecimento de relações entre o novo material a ser aprendido e as ideias relevantes já assimiladas pelos alunos. Com a apresentação do conteúdo pelo professor, almeja-se sua assimilação pelos alunos por meio da comparação com ideias anteriores e consideração das similaridades e diferenças. Compreende-se que a apresentação de casos

\footnotetext{
${ }^{6}$ Variações dos passos formais também foram propostas por Ziller e Waitz, mas a formulação de Rein é a que se firmou historicamente (LARROYO, 1970, p. 685-6).

${ }^{7}$ O professor John S. Brubacher, da Universidade de Yale, proferiu a conferência A importância da teoria na educação em agosto de 1960 no Centro Brasileiro de Pesquisas Educacionais (CBPE) em São Paulo, mediante cooperação com a Fullbright Comission do Brasil. Nessa oportunidade dedicou-se a um exame comparativo entre os métodos de Herbart e Dewey. Com esse texto dialoga a análise crítica de Dermeval Saviani materializada em Escola e Democracia. O conjunto das conferências ministradas pelo convidado foi publicado pelo CBPE, em 1961, em edição bilíngüe, com tradução de Beatriz Osório, com o título A importância da teoria em educação (MENDONÇA et al, 2006).
} 
particulares aos alunos, mediante comparação, permitiria assimilar o princípio geral. A generalização, como passo seguinte, sinaliza a perspectiva de ultrapassar o nível da percepção e do empírico. Por fim, a aplicação consiste na utilização do conhecimento adquirido, embora não em sentido utilitário.

Uma ilustração do método da instrução educativa pode ser encontrada em Larroyo (1970), ainda em sua estruturação original em quatro passos:

\footnotetext{
Um exemplo pode ilustrar a didática dos 'passos formais'. Tema da lição: 'Os planetas'. Primeiro momento do ensino, a clareza ou intuição: observar num planisfério celeste o movimento de algum planeta (Vênus). Segunda fase do processo: comparar Vênus com outros planetas. Terceiro grau do aprendizado ou generalização sistemática: caracterizar em geral esta espécie de astros chamados planetas (definição de planeta). Quarto passo, ou seja, a aplicação do conhecimento adquirido: estabelecer uma comparação entre os planetas e outras classes de astros, formular e resolver problemas astronômicos de distância, de velocidade e assim por diante.

Veja-se como o último passo é um grau de associação mais amplo que o terceiro; mas, como tal, suscetível de servir de base para uma nova sistematização, e assim sucessivamente. Por isso, Herbart preconiza essa método didático à maneira de um processo eficiente para assegurar a continuidade do ensino, pois 'não há verdadeiro ensino senão quando uma noção nova se intercala em seu lugar na série de noções já percebidas e forma uma das malhas do tecido, um dos elos da corrente'. (p. 669).
}

Diante do exposto, clarifica-se a ideia de que se trata de um método pedagógico que reitera o primado do objeto de conbecimento como instrumento para a formação do aluno. Isso não significa, contudo, que a curiosidade e o interesse do aluno sejam desconsiderados ou que não se vislumbre sua participação atenta e ativa, necessária para o alcance das generalizações sistemáticas mediante comparações, bem como na aplicação do conhecimento assimilado.

$\mathrm{Na}$ lição sobre os planetas acima reproduzida podemos constatar que o ponto de partida é o empírico, ou seja, a observação factual de um caso singular, recorrendo-se, na sequência, à comparação como meio para a generalização, por meio de um caminho metodológico cuja direção vai das análises particulares às apreensões gerais, processo no qual a definição formal do conceito tem centralidade. É o que discutiremos em seguida.

\section{APRECIAÇÃO HISTÓRICO-CULTURAL E HISTÓRICO-CRÍTICA DA PEDAGOGIA TRADICIONAL: A CRÍTICA AO VERBALISMO E À “LÓGICA DAS FORMAS”}

Uma vez apresentado o método formal herbartiano e seus nexos internos relacionados à intencionalidade educativa do ensino tradicional, cuja finalidade não pode ser descolada do contexto histórico-social ao qual tal teoria pedagógica é pertencente, é preciso delimitar os limites e as críticas a esta forma de ensino. Para tanto, recorreremos inicialmente às formulações desenvolvidas pelos psicólogos soviéticos da chamada Escola de Vigotski, uma vez que encontramos nas análises acerca das relações entre instrução e desenvolvimento da referida escola um movimento semelhante ao realizado por Saviani no tocante à crítica tanto ao método tradicional quanto aos métodos ativos da pedagogia. 
Na obra Pensamiento y habla, ao se debruçar sobre o problema da formação de conceitos científicos na ontogênese, Vigotski (2012, p. 271) focaliza o problema do "ensino direto de conceitos" e o papel das definições verbais na educação escolar, inserindo-se em um debate propriamente pedagógico em que examina criticamente posições tradicionais e novas no ensino. $\mathrm{O}$ autor corrobora a análise de Tolstói acerca da "impossibilidade de uma transmissão simples e direta do conceito pelo professor ao aluno, da transferência mecânica do significado da palavra de uma mente a outra mediante outras palavras". Tolstói teria captado, em sua própria experiência como educador, um fato fundamental da formação de conceitos, que Vigotski (2012, p. 271) assim formula:

A experiência pedagógica nos ensina, não em menor medida que a investigação teórica, que o ensino direto dos conceitos sempre resulta empiricamente impossível e pedagogicamente infrutífero. O professor que tenta seguir esse caminho habitualmente não consegue nada além de uma assimilação irreflexiva de palavras, um puro verbalismo que simula e imita a presença dos correspondentes conceitos na criança, mas que na realidade encobre um vazio. Nesses casos, a criança não assimila conceitos, mas palavras, capta mais com a memória que com o pensamento, e se mostra incapaz de aplicar com sentido o conhecimento assimilado. Em essência, este modo de ensino dos conceitos é o defeito básico do método puramente escolástico e verbal de ensino que todos condenam, que substitui o domínio dos conhecimentos vivos pela assimilação de esquemas verbais mortos e vazios.

Podemos entender o verbalismo como produto do ensino baseado na expectativa da transferência direta do conhecimento da "cabeça" do professor para a "cabeça" do aluno, do qual resulta a capacidade de verbalizar as definições dos conceitos. A questão é que a definição verbal pode ser memorizada sem que o movimento de pensamento contido no conceito - ou por ele pressuposto seja reconstituído no pensamento do aluno:

[...] o ensino direto de conceitos sempre se mostra impossível e pedagogicamente estéril. O professor que envereda por esse caminho costuma não conseguir senão uma assimilação vazia de palavras, um verbalismo puro e simples que estimula [emula] e imita a existência dos respectivos conceitos na criança mas, na prática, esconde o vazio. Em tais casos, a criança não assimila o conceito mas a palavra, capta mais de memória que de pensamento e sente-se impotente diante de qualquer tentativa de emprego consciente do conhecimento assimilado. No fundo, esse método de ensino de conceitos é a falha principal do rejeitado método puramente escolástico de ensino, que substitui a apreensão do conhecimento vivo pela apreensão de esquemas verbais mortos e vazios (VIGOTSKI, 2001, p. 247).

Se Vigotski (2012) considera acertada a crítica de Tolstói, pondera, ao mesmo tempo, a exagerada importância que este atribui à espontaneidade e ao papel das representações e sensações intuitivas no processo de formação de conceitos. O aspecto errôneo da posição pedagógica de Tolstói é, em sua análise, "excluir toda possibilidade concreta de intervir nesse enigmático processo" (p. 273), condenando o ensino a um papel muito passivo no desenvolvimento dos conceitos científicos. Tal posição deriva de - ou apoia-se em - uma dicotomia entre desenvolvimento do pensamento e ensino de conceitos, a partir da qual se advoga deixar o processo de desenvolvimento dos conceitos abandonado a seu próprio curso interno. 
A síntese de Vigotski (2012, p. 275), elaborada a partir da crítica tanto ao método tradicional-escolástico quanto aos métodos de corte espontaneísta e verificada experimentalmente, é que "[...] é possível realizar um trabalho direto sobre o conceito durante o processo de ensino escolar", ou seja, que "[...] o ensino deliberado de novos conceitos e formas ao aluno não somente é possível, mas pode também ser a origem do desenvolvimento superior dos próprios conceitos já formados na criança". Conforme postulou o autor, "[...] os conceitos científicos não são assimilados nem decorados pela criança, não são memorizados mas surgem e se constituem por meio de uma imensa tensão de toda a atividade do seu próprio pensamento" (VIGOTSKI, 2001, p. 260).

Necessário ressaltar que a crítica feita por Vigotski ao ensino tradicional no que toca à questão da formação de conceitos e ao desenvolvimento do pensamento não autoriza nenhum tipo de vinculação de seu pensamento ao espontaneísmo pregado pelos métodos novos de ensino. Há, em sua teorização, uma clara posição favorável ao ensino de conceitos científicos; o foco de sua problematização é o papel da definição verbal, da memória e do pensamento no processo de transmissão-formação de conceitos. A transferência direta do conceito do professor para o aluno por meio da apresentação de sua definição verbal: eis o que Vigotski questiona e considera impossível ou ineficaz. $O$ autor nos ajuda a compreender que o conceito é assimilado pelo aluno mediante um processo de formação que demanda atividade intelectual, ou seja, requer a reorganização e constituição de novas operações do pensamento.

Ao assumir a psicologia histórico-cultural como fundamento da práxis pedagógica, a pedagogia histórico-crítica reitera a crítica ao verbalismo que se consolidou como tendência no ensino tradicional, recusando a compreensão do ensino como apresentação do conhecimento. A verdadeira transmissão-assimilação de conceitos ocorre quando o movimento do pensamento contido nos sistemas conceituais se reconstitui no pensamento do aluno, instituindo-se como possibilidade intrapsíquica, incorporando-se como ferramenta de análise em sua relação ativa com a realidade.

Embora tenhamos identificado na pedagogia tradicional em sua formulação herbartiana o primado do objeto de conhecimento, que é corroborado pela pedagogia histórico-crítica, podemos reconhecer diferenças na compreensão do processo pelo qual o objeto de conhecimento é efetivamente incorporado pelo aluno. O método da instrução educativa, ao colocar centralidade na apresentação ou "demonstração do objeto" pelo professor e em sua definição (verbal), deixa de captar toda a complexidade envolvida no processo de formação de conceitos, ainda que reafirme a importância da continuidade e a própria ideia de sistemas de representação ${ }^{8}$. Recorrendo ao parecer de Larroyo (1970, p. 666), podemos cogitar que os fundamentos psicológicos sobre os quais se apoia Herbart limitam essa apreensão concreta: "em suma: a Psicologia de Herbart pode ser caracterizada como metafísica, intelectualista, associacionista, mecanicista e matemática".

Avançando além da crítica ao verbalismo, cujo alerta central é o risco de que o ensino se resuma a promover uma assimilação vazia e irreflexiva de palavras apoiada muito mais na memória do que no raciocínio, buscamos nas contribuições do psicólogo Vasili Davydov (2008) novos elementos para a discussão dos impactos do ensino tradicional sobre a formação do pensamento dos alunos. Apoiado nas proposições vigotskianas, Davydov (2008) teoriza o desenvolvimento do pensamento

8 Como anteriormente apresentado, Herbart postula que não há verdadeiro ensino senão quando uma noção se intercala em seu lugar na série de noções já percebidas como um novo elo da corrente.

Educação em Revista|Belo Horizonte|v.36|e221954|2020 
humano a partir da diferenciação entre suas formas empírica e teórica. Em nossa avaliação, a elaboração desse autor traz contribuições decisivas para a edificação da teoria histórico-crítica na pedagogia, ao permitir delimitar a formação do pensamento teórico como norte da práxis pedagógica.

Os princípios do método materialista dialético constituem a base da análise que Davydov desenvolveu sobre o pensamento humano. $\mathrm{O}$ autor caracteriza duas diferentes formas pelas quais o pensamento humano se relaciona com a realidade, as quais denominou pensamento empírico e o pensamento teórico.

Segundo Davydov (2008), o pensamento empírico é o início da cognição racional; permite separar e abstrair objetos, incluindo processos de pensamento como indução, dedução, abstração, análise, síntese e experimentação. Por meio desses processos, objetos podem ser claramente separados e distinguidos, levando a uma generalização, mas que permanece no plano formal ou abstrato: "diferenciação e classificação são precisamente as funções das concepções gerais ou conceitos empíricos" (DAVYDOV, 2008, p. 93). Generalizações empíricas são resultado de observações sensoriais descritas verbalmente, partindo do particular para o geral. Resultando da ascensão do sensível e (pseudo)concreto para o mental e abstrato, elas revelam os atributos externos identificadores de objetos que o tornam parte de uma mesma categoria geral. Disso pode-se concluir que o conteúdo dos conceitos empíricos é idêntico ao originalmente dado na percepção. Conforme Kopnin (1978, p. 152): "no pensamento empírico o objeto é representado no aspecto das suas relações e manifestações exteriores acessíveis à contemplação viva. [...] Em nível empírico obtém-se da experiência imediata o conteúdo fundamental do pensamento".

O pensamento empírico é essencialmente baseado na lógica formal, revelando o imediato na realidade. Generalizações empíricas apenas captam a repetibilidade, semelhança e diferenciação externas. Assim, podemos dizer, com Davydov (2008), que o pensamento empírico não opera propriamente com conceitos, mas com concepções gerais formadas por representações ideais.

Segundo Davydov (2008, p. 90), o pensamento empírico é um importante elemento da cognição humana, uma vez que ele “[...] dá aos seres humanos ampla capacidade de separar e nomear objetos e suas relações, incluindo aquelas que não são observáveis em um determinado momento mas precisam ser deduzidas indiretamente". Contudo, não deve ser entendido como idêntico ao pensamento em geral, e não deveria ter um papel primário e independente no processo de desenvolvimento do pensamento. Ao contrário, deve ser entendido e ter seu desenvolvimento promovido como um dos elementos do pensamento teórico - assim, como a lógica formal deve ser entendida como um elemento incorporado (por superação) à lógica dialética. E este é um dos elementos centrais - o que não significa o único - da diferença essencial da pedagogia histórico-crítica dos métodos tradicionais de ensino, como buscaremos evidenciar.

Conceitos empíricos e teóricos diferem tanto em conteúdo quanto na forma. $\mathrm{O}$ pensamento teórico é essencialmente baseado na lógica dialética e tem, portanto, um caráter mediado. Seu conteúdo não é o imediato na realidade, mas o "ser mediado, refletido, essencial" (DAVYDOV, 2008, p. 90). O pensamento teórico opera com conceitos propriamente ditos, os quais penetram nas conexões internas do fenômeno: "um conceito, de acordo com Hegel, expressa a essência dos fenômenos contemplados” (ILYENKOV, 2008, p. 48).

Essa formulação é convergente com a proposição vigotskiana segundo a qual a formação de conceitos científicos - os que ele mesmo denominava de "os verdadeiros conceitos" - é 
determinante para o desenvolvimento de um psiquismo apto a captar a realidade objetiva idealmente, conferindo-lhe inteligibilidade. A tomada de consciência do real, de acordo com o autor, é dependente de formas de pensamento que operam sob a base de contínuos atos de generalização, dentro de um sistema hierárquico de inúmeras estruturas de generalizações conceituais internamente conectadas de forma interdependente, o que somente é possível por meio do desenvolvimento do pensamento teórico-conceitual. Desse modo, afirma o autor, "a tomada de consciência passa pelos portões dos conceitos científicos" (VIGOTSKI, 2001, p. 290).

O verdadeiro conceito, ou conceito teórico, desvela as transições e conexões mútuas no interior de um determinado todo e em dependência desse todo, ou seja, desse sistema holístico, indicando o peso e o papel específico do objeto no interior desse todo: "o conteúdo do pensamento teórico é a esfera dos fenômenos interagindo objetivamente entre si constituindo um sistema holístico. Sem um sistema holístico, ou fora dele, estes fenômenos são meramente o objeto de estudo empírico" (ILYENKOV, 2008, p. 92).

O processo de desenvolvimento ou formação do sistema em si mesmo também é revelado. O conceito teórico “[...] não apenas inclui o que é idêntico em cada singular objeto da classe, mas também busca a interconexão dos objetos singulares no interior do todo, no interior do sistema de seu vir-a-ser" (ILYENKOV, 2008, p. 93). Assim, a compreensão teórica do fenômeno revela a conexão entre o individual e o universal, o externo e o interno. Ela pretende revelar o conteúdo universal dos objetos, inserindo-os em um sistema e formando uma teoria que corresponde a seu conteúdo interno.

Embora sensações sejam a fonte de todas as formas de cognição, incluindo do pensamento teórico, conceitos não são derivados diretamente das observações sensoriais da realidade, como ocorre com as concepções empíricas: "[...] dependências internas e essenciais não podem ser observadas diretamente, já que elas não são dadas em um ser que é fixo, finalizado, e diferenciado. O interno é observado em mediações, em um sistema, no vir-a-ser de um todo" (ILYENKOV, 2008, p. 93). Assim, em um conceito teórico, o observável é correlacionado com o passado e com o potencial futuro do fenômeno - seu vir-a-ser: "pensamento dialético [teórico] revela transições, movimento e desenvolvimento” (ILYENKOV, 2008, p. 78).

A essência de um objeto só pode ser revelada estudando-se o processo de sua origem e desenvolvimento. Dessa forma, o pensamento teórico busca apreender a fonte do fenômeno, sua gênese, as razões internas e as condições da origem do objeto. Nas palavras de Davydov (2008, p. 98), isso significa compreender: "a que propósito e por que, em que base, com que potencial o objeto veio a existir nessa forma e não em outra". Esta apreensão das relações internas essenciais que organizam o fenômeno é a base para intervenções que resultam em reais transformações do objeto, ou seja, transformações para além da superfície, que alcançam a essência do fenômeno.

$\mathrm{O}$ uso de ações mentais para perseguir o processo de formação do concreto é o pensamento na forma de conceitos, isto é, o pensamento teórico. Trata-se de um "método especial de reflexão da realidade, que a conhece de forma mais profunda e precisa" (DAVYDOV, 2008, p. 98). Segundo a teorização de Davydov (2008), gênese (origem), movimento (desenvolvimento histórico) e sistema holístico (todo) parecem ser os pontos chave do pensamento teórico, o qual é capaz de reproduzir a realidade concreta como a unidade do diverso por meio da ascensão do abstrato ao concreto. 
Em face da teorização de Davydov (2008) que buscamos aqui sintetizar, cabe-nos retomar a análise crítica do método da instrução educativa como expressão da pedagogia tradicional, tendo em vista aclarar suas diferenças face à pedagogia histórico-crítica. Ao preconizar o trânsito do particular para o geral, o método tradicional tem como tendência promover majoritariamente a formação do pensamento empírico. Como vimos, as generalizações empíricas resultam da ascensão do sensível para o mental e abstrato, sendo capazes de revelar os atributos externos identificadores de objetos que o tornam parte de uma mesma categoria geral, mas incapazes de revelar efetivamente as relações dinâmico-causais que produzem e sustentam os fenômenos. Em nossa análise, o método tradicional se detém nesse limite, na medida em que estabelece o empírico como ponto de partida e a abstração como ponto de chegada.

O destaque nesse método aos procedimentos de comparação e associação converge com o movimento de formação de generalizações empíricas elucidado a partir de Davydov (2008), permitindo captar a repetibilidade, semelhança e diferenciação externas dos fenômenos. Retomando a lição sobre os planetas, podemos recordar as orientações didáticas de comparar Vênus com outros planetas, caracterizar a espécie de astros chamados planetas (apresentando uma definição de planeta), fazer comparação entre os planetas e outras espécies de astros. Tais procedimentos conduzem à formação de concepções gerais em cuja base encontram-se representações ideais e abstrações elementares, mas não permitem alcançar o grau de generalidade das abstrações autênticas.

Fazemos referência aqui à distinção delimitada por Kopnin (1978, p. 160) entre abstrações elementares e abstrações autênticas. Segundo ele, as abstrações elementares são constitutivas da forma lógica de desenvolvimento do pensamento empírico, sendo aquelas que se limitam a separar elementos, "isolar um dos outros os indícios sensorialmente perceptíveis", podendo-se chegar a formação de uma classe de objetos ou fenômenos possuidores dos mesmos indícios. Porém, afirma o autor, “[...] se o conteúdo da abstração se limitasse a isto, as abstrações seriam terrivelmente pobres de conteúdo, não poderiam refletir a natureza [do objeto] com mais profundidade, fidelidade, plenitude".

$\mathrm{O}$ argumento que sustentamos é que a isto se limita o método tradicional de ensino. Ao método pedagógico histórico-crítico, por sua vez, se coloca a tarefa de formação e desenvolvimento das abstrações autênticas, as que permitem "[...] descobrir novos aspectos no objeto que traduzam as relações de essência” (KOPNIN, 1978, p. 161). Com base nessa propositura é que Saviani explicitou o método pedagógico que busca superar o empírico pelo concreto por meio do abstrato.

O processo do conhecimento direcionado ao alcance da essência de um dado objeto ou fenômeno exige, conforme nos legou Marx (2011), um método de ascensão do abstrato ao concreto, ou seja, um percurso metodológico que permita ao sujeito superar a condição inicial de carência e ausência de determinações - por isso uma relação abstrata - para com tal objeto ou fenômeno, permitindo a este sujeito que busca conhecê-lo cada vez mais ir apreendendo-o em sua concretude real e objetiva, apropriando-se de seu movimento contraditório que se expressa em seu vir-a-ser. Kopnin (1978, p. 154) nos ajuda a compreender o método de ascensão do abstrato ao concreto delimitado por Marx:

O abstrato e o concreto são categorias da dialética materialista elaboradas para refletir a mudança da imagem cognitiva tanto no que concerne à multilateralidade da abrangência do objeto nessa imagem quanto à profundidade da penetração na essência dele (destaque do autor). 
Quando nos referimos ao método de ascensão do abstrato ao concreto, estamos nos pautando na concepção metodológica de Marx (2011) cujo enfoque de explicitação do movimento do conhecimento objetivo e verdadeiro da realidade corresponde à forma lógica do pensamento que se movimenta da definição abstrata (carente de determinações e relações mediadas) à apreensão da totalidade concreta (concreto enquanto unidade de síntese de múltiplas determinações e relações numerosas).

Kopnin (1978) sustenta a afirmação de que a formação das abstrações elementares não permite a formação do pensamento teórico, este que é capaz de reproduzir o concreto como processo de síntese, como resultado do processo de conhecimento, em que pese, afirmara Marx (2011), seja o verdadeiro ponto de partida para a ação e intervenção na realidade:

O concreto no pensamento é o conbecimento mais profundo e substancial dos fenômenos da realidade, pois reflete com seu conteúdo não as definibilidades exteriores do objeto em sua relação imediata, acessível à contemplação viva, mas diversos aspectos substanciais, conexões, relações em sua vinculação interna necessária. Abstrações isoladas elevam o nosso conhecimento da apreensão do geral empírico ao universal, enquanto o concreto no pensamento fundamenta a conexão do singular com o universal, fornece não uma simples unidade de aspectos diversos mas a identidade dos contrários (KOPNIN, 1978, p. 162) (destaque do autor).

É por meio desta concepção metodológica que a pedagogia histórica-crítica se diferencia do método indutivo tradicional do ensino, superando a representação ideal que se forma neste método de nível empírico-sensorial, em direção aos verdadeiros conceitos que se formam sob a base de abstrações autênticas que permitem a descoberta de novas propriedades, de aspectos essenciais e relações internas dinamizadas por aspectos contraditórios imanentes à ordem do 'ser' do próprio objeto do conhecimento.

Não é por acaso, portanto, que Dermeval Saviani coerentemente desenvolveu o método pedagógico histórico-crítico como aquele que toma a prática social como ponto de partida e de chegada da prática educativa, tendo como elementos intermediários os momentos de problematização, instrumentalização e catarse, bem como, desenvolveu o conceito de educação como mediação na prática social global. O desafio de se pensar uma didática para a pedagogia histórico-crítica implica a clareza de que a transmissão do conhecimento não se apresenta como fim em si mesmo, mas meio, ou seja, almejando que o conhecimento acumulado e arduamente conquistado por inúmeras gerações de seres humanos no enfrentamento com os dramas e problemas impostos pela prática social possa converter-se em patrimônio pessoal do aluno, instrumento que se interpõe em sua relação com a realidade, transformando essa relação e requalificando-o para nela intervir como verdadeiro sujeito da práxis.

Ao pontuarmos a conexão entre conhecimento e prática social em uma perspectiva crítica e demarcarmos que o ensino não se confunde com a verbalização ou apresentação do conhecimento, fica evidenciada a enorme diferença entre a pedagogia histórico-crítica e o assim chamado ensino tradicional. Buscamos notabilizar que a pedagogia histórico-crítica conserva da pedagogia tradicional o princípio da transmissão do conhecimento para todos, mas realiza-o a partir de outro método, pautado pela concepção de conhecimento materialista histórico-dialética, o que significa advogar a transmissãoassimilação do conhecimento verdadeiramente conceitual, teórico, concreto, concebido como mediação 
da atividade consciente da pessoa no mundo. Assim, ressaltamos que o princípio da transmissãoassimilação do conhecimento teórico subordina-se a uma finalidade pedagógica e política divergente do ensino tradicional, à medida que vislumbra a práxis que transforma a realidade social.

O reconhecimento de tais diferenças não nos autoriza, entretanto, a comungar do posicionamento negativo dos métodos novos quanto ao ato de ensinar, o que salientaremos na seção a seguir, que conclui o artigo.

\section{À GUISA DE CONCLUSÃO: O MÉTODO PEDAGÓGICO HISTÓRICO-CRÍTICO E O PROBLEMA DA TRANSMISSÃO DO CONHECIMENTO}

O escolanovismo e, mais amplamente, o ideário do "aprender a aprender", consideram as aprendizagens que o indivíduo realiza por si mesmo como mais desejáveis do que aquelas que se realizam pelo intercâmbio da criança com o adulto, par mais experiente e mais desenvolvido (DUARTE, 2011). Tal enaltecimento daquilo que se alcança por si mesmo é consoante com o individualismo que impera no reino neoliberal. Em nossa avaliação, essa posição ofusca a beleza do ato de ensinar!

Transmitir a uma criança conhecimentos que foram historicamente conquistados e sistematizados pelo trabalho de muitas e muitas gerações de seres humanos, oferecendo a ela instrumentos para melhor se orientar no mundo, é um ato profundamente belo. Legar como herança o conhecimento sobre a realidade que se pôde conquistar e elaborar coletiva e historicamente, como conjunto de ferramentas que possam ser incorporadas por toda criança e guiar sua atividade no mundo, é expressão radical de nossa condição de seres sociais e históricos que não se constituem humanos senão na relação com o outro.

No cenário contemporâneo dominado pelo ideário pós-moderno, neoliberal e construtivista (DUARTE, 2011), agregou-se à ideia de transmissão do conhecimento uma conotação pejorativa. É necessário resgatar seu sentido essencial, refutando e superando a caricatura que tem sido continuamente reposta, que veicula a risível noção de que transmitir conteúdos equivale a um deslocamento físico-espacial do conhecimento da "cabeça do professor" para a "cabeça do aluno". Tal conotação tem servido de sustentáculo à ideia de que a escola que transmite arte, ciência e filosofia impõe um processo passivo e de coerção para os alunos.

Concordamos com a formulação de Abrantes (2015), para quem a transmissão do conhecimento não significa restrição da liberdade de pensar, mas sua condição, vez que a possibilidade de decodificar a realidade para além das aparências é uma conquista humana que somente pode se realizar na existência individual a partir da apropriação dos conhecimentos sistematizados. O pensar, afinal, pressupõe objeto, meios (ferramentas conceituais) e método, o que atesta a impossibilidade de desenvolvimento do pensamento apartado do conhecimento, ou de movimento do pensamento que não seja alicerçado, sustentado e guiado pelos conteúdos conceituais da cultura.

Queremos enfatizar que a defesa da transmissão às novas gerações, pela escola, do conhecimento metódico, historicamente sistematizado, aquele que permite ir além das aparências desvelando as determinações essenciais dos fenômenos, nos parece ganhar inédita relevância no 
presente momento histórico que atravessa nosso país, marcado por aquilo que Duarte (2018) tem denominado "obscurantismo beligerante". Obscurantismo é definido pelo Dicionário UNESP do português contemporâneo (BORBA, 2004) como atitude ou política contrária à divulgação e transmissão do conhecimento. A expressão cunhada por Duarte (2018) nos parece acertada frente ao cenário marcado por toda sorte de ataques à ciência (tanto em âmbito ideológico quanto em termos da fragilização das condições materiais necessárias ao desenvolvimento de pesquisa e tecnologia em território nacional), pela implementação de medidas governamentais desprovidas de fundamento (a exemplo da recente campanha pelo adiamento do início da vida sexual como estratégia de combate à gravidez na adolescência), e pelo triunfo da divulgação de informações falsas e/ou distorcidas como estratégia de manipulação da opinião pública. Ante esse quadro, é mais do que nunca necessário disputar a escola como instituição que tem a potencialidade de contribuir para a formação de uma visão de mundo imune à mistificação do real, transmitindo aos filhos da classe trabalhadora conhecimentos que refletem fidedignamente a realidade natural e social, assim provocando e promovendo a capacidade de questionar, comparar, generalizar, estabelecer relações, enfim, de análise e explicação dos objetos e fenômenos.

Ao demarcar a divergência entre a pedagogia histórico-crítica e a pedagogia tradicional ao longo desse texto, esperamos ter evidenciando que a defesa da transmissão do conhecimento sistematizado pela escola é um princípio da esfera ontológica, que se refere à natureza e especificidade da atividade educativa, e não à dimensão didático-operacional do ato educativo, como suposta entrega ou transferência direta do saber. Isso significa dizer que a transmissão do conhecimento não se situa no âmbito da forma do ensino, mas, a rigor, de sua intencionalidade.

É na exata medida em que se compreende o processo de transmissão de conhecimento como um princípio de esfera ontológica do processo educativo que a pedagogia histórico-crítica o defende como configuração clássica e essencial da atividade de ensino. Transmissão de conhecimentos não é condição de exclusividade de uma ou outra teoria pedagógica. É um traço essencial da educação escolar (SAVIANI, 2013b). Tal qual nos legou Vigotski (2001, p. 251), abordando a relação entre ensino e desenvolvimento, "[...] a instrução [obutchenie] é, na idade escolar, o momento decisivo e determinante de todo o destino do desenvolvimento intelectual da criança, inclusive do desenvolvimento dos seus conceitos".

O conhecimento sistematizado historicamente pelos seres humanos pode ser transmitido às novas gerações por diversas formas, inclusive, mas não somente, por aulas expositivas e preleções. $\mathrm{O}$ que buscamos sublinhar é que a transmissão do conhecimento advogada pela pedagogia históricocrítica não se confunde com a apresentação ou verbalização de conhecimentos pelo professor, nem se confirma por sua verbalização e fixação mnemônica pelo aluno: a questão que se coloca é como organizar a atividade escolar do estudante para que nela se reconstitua a atividade intelectual e prática historicamente acumulada e sintetizada nos sistemas conceituais das diversas áreas do conhecimento e da prática social, para que tais sistemas conceituais se tornem elementos mediadores da atividade social dos estudantes, ensejando a práxis. 


\section{REFERÊNCIAS}

ABRANTES, A. A. Educação escolar e acesso ao conhecimento: o ensino como socialização da liberdade de pensar. Germinal: Marxismo e Educação em Debate, Salvador, v.7, n.1, p.132-140, jun. 2015.

AZEVEDO, F. et al. O Manifesto dos Pioneiros da Educação Nova. Revista HISTEDBR On-line, Campinas, n. especial, pp.188-204, ago. 2006.

BORBA, F. S. (org.) Dicionário UNESP do Português Contemporâneo. São Paulo, Editora UNESP, 2004.

BRUBACHER, J. S. A importância da teoria em educação. Rio de Janeiro: INEP, 1961.

CAMBI, F. História da Pedagogia. Tradução de Álvaro Lorencini. São Paulo: Editora da UNESP, 1999.

CARVALHO, R. M. B. Georges Snyders: em busca da alegria na escola. Perspectiva, v.17, n.32, p.151170, Florianópolis, dez.1999.

DAVYDOV, V. V. Problems of developmental instruction: a theoretical and experimental psychological study. Translated by Peter Moxhay. Nova Science Publishers, 2008.

DUARTE, N. O currículo em tempos de obscurantismo beligerante. Rev. Espaço do Currículo (online), v. 11, n. 2, p. 139-145, mai./ago. 2018.

DUARTE, N. Vigotski e o "aprender a aprender": crítica às apropriações neoliberais e pósmodernas da teoria vigotskiana. $5^{a}$ ed. Campinas-SP: Autores Associados, 2011.

GIL, A. C. Métodos e técnicas de pesquisa social. 6ª ed. São Paulo: Atlas, 2008.

HILGENHEGER, N. Johann Friedrich Herbart (1776-1841). In: Perspectives: Revue Trimestrielle de l'Éducation Comparée, v. XXIII, n. 3-4, 1993 (Paris, UNESCO: Bureau International d'éducation). Tradução de José Carlos Libâneo. Disponível em: < http://principo.org/johann-friedrich-herbart-177618411.html>. Acesso em 19 mar 2019.

ILYENKOV, E. V. The dialectics of the abstract and the concrete in Marx's Capital. Delhi: Aakar Books, 2008.

KOPNIN, P. V. A dialética como lógica e teoria do conhecimento. Rio de Janeiro: Civilização Brasileira, 1978.

LARroyo, F. História Geral da Pedagogia. Tomo II. Tradução de Luiz Aparecido Caruso. 10ª ed. ampliada. São Paulo: Editora Mestre Jou, 1970.

MAFRA, J. F. O ser humano integral e o humanismo científico de Suchodolski. In: WOJNAR, I.; MAFRA, J. F. (Orgs.). Bogdan Suchodolski. Recife: Fundação Joaquim Nabuco, Editora Massangana, 2010. pp. 37-49.

MARX, K. Grundrisse: manuscritos econômicos de 1857-1858: esboço da crítica da economia política. São Paulo: Boitempo; Rio de Janeiro: EDUFRJ, 2011. 
MENDONÇA, Ana Waleska P. C. et al . Pragmatismo e desenvolvimentismo no pensamento educacional brasileiro dos anos de 1950/1960. Rev. Bras. Educ., Rio de Janeiro , v.11, n.31, pp. 96113, Apr. 2006. Disponível em: <http://www.scielo.br/scielo.php?script=sci_arttext\&pid=S1413$24782006000100008 \& \operatorname{lng}=\mathrm{en} \& \mathrm{nrm}=\mathrm{iso}>$. Acesso em 19 mar 2019.

SAVIANI, D. Pedagogia histórico-crítica: primeiras aproximações. 11 a ed. Campinas, SP: Autores Associados, 2013a.

SAVIANI, D. Educação: do senso comum à consciência filosófica. 19a ed. Campinas-SP: Autores Associados, 2013b.

SAVIANI, D. Escola e democracia. 42a ed. Campinas-SP: Autores Associados, 2012.

SNYDERS, G. Pedagogia progressista. Coimbra: Livraria Almedina, 1974.

SUCHODOLSKI, B. A pedagogia e as grandes correntes filosóficas. In: WOJNAR, I.; MAFRA, J. F. (Orgs.). Bogdan Suchodolski. Recife: Fundação Joaquim Nabuco, Editora Massangana, 2010.

TRIVIÑOS, A. N. S. Introdução à pesquisa em ciências sociais: a pesquisa qualitativa em educação. $5^{\text {a }}$ ed. São Paulo: Atlas, 2009.

VIGOTSKI, L. Pensamiento y habla. Buenos Aires: Colihue, 2012.

VIGOTSKI, L. S. A construção do pensamento e da linguagem. São Paulo: WMF Martins Fontes, 2001.

Submetido: $28 / 03 / 2019$

Aprovado: 22/03/2020 